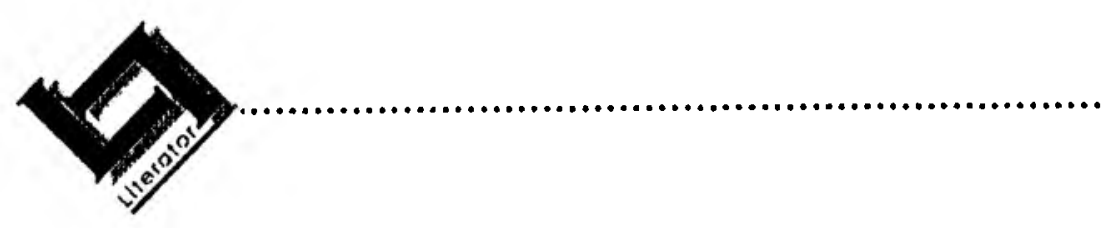

\title{
Die engel op die vlaktelandskap
}

\author{
G.A. Jooste
}

Departement Afrlkaans

Unlversltelt Vista

Port Ellzabeth-kampus

PORT ELIZABETH

E-pos: Jste-ga@pellcan.vista.ac.za

\section{Abstract}

\section{The angel on the plains}

This article about Die uur van dle engel (Karel Schoeman, 1995) examines relationship benveen the inhabitants of the barren Free State and its landscape. Most people are limited by a "horizontal" approach to life; they are unable to fulfil their desires. The novel reveals a reason why some people find peace in such an inhospilable landscape while others seem to find merely temporary success in terms of possessions or power, but vanish from the landscape with hardly a trace left behind. This article contends that the angel, as a "vertical" factor, makes the real difference. The presence of the angel invites a symbolic reading of relationships with the landscape, in that the novel presents the angel with all its assosiations of mercy (as a manifestation of a suggested secret). This view opens the possibility for an ending that contains a healing message: life is after all, possible on the barren plains of Africa because of a spiritual approach.

\section{Inleldling}

Die ruimte in Karel Schoeman se oeuvre is 'n ondersoekveld wat gereed lê vir verkenning.

Sedert 'n Lug vol helder wolke (1967) klee Schoeman die Afrika-landskap uitvoerig en in besonderhede in as ' $n$ formidabele teenspeler vir die soekende mens. Dit blyk uit talle verwysings na die land in die titels van sy romans: $O p$ 'n eiland (1971), $\mathrm{Na}$ die geliefde land (1972), Afrika: 'n roman (1977), ' $n$ Ander land (1984). Sy romanfigure tree met die landskap in interaksie, nie noodwendig omdat hulle soos pionierboertipes, byvoorbeeld die Moolmans van Toorberg (vgl. 
Van Heerden, 1986) en talle ander in Afrikaanse plaasromans, daarvan besit wil neem en dit wil onderwerp nie, maar omdat 'n verhouding met die Afrikalandskap gewoon onontkombaar is as ' $n$ mens in Afrika woon.

Dit gaan in hierdie artikel hoofsaaklik om die landskap in Die uur van die engel, maar ander romans van Schoeman word ook betrek. Die artikel verken betekenisvolle verhoudinge tussen 'n sekere landskap, naamlik die Suid-Vrystaat, en die mense wat daar gewoon het en nog daar woon. Die landskap kom uit die verf; saam daarmee word die aard van die menslike bestaan op die vlakte oopgedek. Spore van 'n vorige bestaan kan uitgeken word, selfs in 'n lee en grotendeels verlate landskap soos die hedendaagse Suid-Vrystaat. Die landskap en die verhoudinge tussen mense en die land, in verskillende tye van Suid-Afrika se geskiedenis, word getematiseer om aspekte van die menslike bestaan aan die orde te stel.

Die uur van die engel onthul die meestal versweè maar wesenlike aspekte van menseverhoudinge nogal genadeloos, en skakel in hierdie opsig met Afrika: 'n roman. In laasgenoemde word vertel hoe die jong fotograaf, Gisela, haar bemoei om te sien wat oorbly wanneer die sier en tooisel van die menslike beskawing afgestroop word. Aan hierdie moeitevolle proses word die lewens van mense in haar kenniskring, maar ook die stad Glasgow en omringende landskap onderwerp. Die landskap in Die uur van die engel het veel minder sier en tooisel as die Skotse stad. Die essensie van die menslike bestaan staan duideliker gedefinieer, maar die doel bly dieselfde.

Met die plasing van mense in sekere situasies in landskappe word sekere diskursiewe effekte bereik. Die landskap is bepalend. Die vlakte van Die uur van die engel is byvoorbeeld tegelyk 'n "wye, lee panorama" (Schoeman, 1995:79) waarin spore van die menslike bestaan maklik verdwyn én 'n lewensbeperkende ruimte omdat dit so kaal is. Daar is 'n ironiese kontras tussen die grootte van die onherbergsame landskap en die beperkte menslike lewe wat daarbinne moontlik is. Soos in die meeste Schoeman-romans word die epiese middele aangewend om veral op interpersoonlike verhoudinge te fokus. Ook hierin teken beperkende kleinheid en kleinlikheid die verhoudinge.

Hierdie ontleding kyk na manifestasies van die ruimte met die doel om deur interpretasie aan te dui dat daar ' $n$ spanning tussen vertikale en horisontale ruimtes geskep word. Hierin speel 'n geümpliseerde skakel tussen die berg as simboliese ruimte en die engel van die Heer as verlossende simbool mee. Die artikel ondersoek die manifestasies van lewe-in-die-ruimte met die oog op oorlewingsmoontlikhede ten einde aan te toon hoe oorlewing met die patroon vertikaal/horisontaal saamhang, en watter rol die engel van die Heer speel. 


\section{Die Afrika-landskap as ruimte}

Ruimte is eerstens plek en agtergrond in die sin van storieruimte (vgl. Venter, 1992:453). Die soektog na betekenis in hierdie landskap verreken behalwe die mimetiese aspek van die ruimte ook die verhoudinge tussen mense en dinge in die landskap. Dit gaan om oorlewing. Hierdie boodskap staan nie net in die storie nie, maar word uitgedruk in patrone in die sogenaamde verhaalruimte. Dit is byvoorbeeld 'n patroon soos vertikalisme teenoor horisontalisme, wat verder aan in die artikel ondersoek word.

Daar word ook gekyk na attribute van die landskap wat elk as sinekdogee inpas by die sogenaamde totale ruimte (Zoran, 1984:329). Die totale ruimte is die allesomvattende tydruimtelike verband, die geimpliseerde geheel, groter as die som van die fiktiewe nuimtes wat in die roman voorgestel word. Binne die totale ruimte van Die uur van die engel tref die leser gewone besonderhede as ruimtelike attribute aan: die dorp met sy geboue en interieurs, plase en die veld, paaie. Rondom die naamlose dorp in die suidelike Vrystaat, moontlik 'n plek soos Trompsburg, dein 'n wye landskap; bokant stolp 'n eindelose blou hemel. Die land oorheers die mensies en menslike strukture in die oewerlose stroom van die tyd. Die ewige landskap strek onbesitbaar en onmeetbaar na alle kante uit, maar ook die grootte, die duiselingwekkende leegheid (Schoeman, 1995:119) en die wesenlike ontembaarheid van die Afrika-landskap spreek uit die merk wat dit laat op elke ruimtelike attribuut, veral die mensgemaaktes. 'n Mens dink onwillekeurig aan onontkombare verval: “... die bouval van 'n huis, die toegegroeide graf, die ongemerkte klip" (Schoeman, 1995:6).

Dié totale ruimte sluit dus alle "werklike" en geïmpliseerde ruimtes in, myns insiens ook simboliese ruimte, en as sodanig is dit tegelyk eindeloos én diffuus, in elk geval te abstrak om "waargeneem" te word. Dit leef egter in dele, ook as 'n kragveld waarin die dele met mekaar in interaksie tree. Die leser van die roman ervaar die totale ruimte as sowel die durende konteks waarbinne die geskiedenis en die mites van die land hulself manifesteer as alle romanmatige manifestasies van die nimte. Die uur van die engel teken 'n reeks beelde van die geskiedenis en die mites van die mense in die totale nuimte wat daardie deel van die OranjeVrystaat in Suid-Afrika was, van vroeg in die vorige eeu tot by die hede.

Die waarneming van Afrika vanuit 'n hoofsaaklik Europese afstand en kyksfeer, eie aan party van Schoeman se vroeëre romans, byvoorbeeld $O p$ ' $n$ eiland (1971), Die noorderlig (1975), Afrika: 'n roman (1977) en Die hemeltuin (1979), aksentueer diskursief sekere attribute van Afrika taamlik skerp (Jooste, 1995:251 e.v.). So 'n blik vanuit Europa moet uit die verte rekening hou met die afstand tussen Europa en Afrika, maar ook met die feit dat Afrika nie die enigste land is wat in ag geneem moct word nie. Afrika is vol in beeld, maar 'n Furopese werklikheid is deel van die kykraam. So word die waaneming beïnvloed en 
Afrika gekleur. In mindere of meerdere mate roep so 'n Europees georienteerde blik op Afrika, in Schoeman se oeuvre, die bekende vensterbeeld op. In ' $n$ Ander land word hierdie visie so verwoord: "Afrika self sien ons net op ' $n$ afstand deur die kantgordyntjies wat ons in ons woonkamervensters opgehang het" (Schoeman, 1984:222). Vanuit hierdie perspektief word 'n Eurosentriese verhouding tussen die kyker(s), die ons, en die landskap daar buite gepresiseer. Die plasing van die kyk oor ' $n$ afstand en deur 'n raam het die effek dat die harde Afrikawerklikheid van 'n Ander land enigermate ontwerklik word (vgl. ook Venter, 1985) deurdat dit weggeskuif word, tot prent gereduseer word en bekyk word vanuit die veilige binnekant van 'n Europese tipe huis.

Afrika van ver is anders en vreemd, ' $n$ ander land en ' $n$ ander werklikheid. Afrika staan ook vir onvoorspelbare verandering. Afrika is 'n nagmerrie van onbestendigheid, 'n vyandige gebied wat die Europese mens nie wil aanvaar nie, 'n onvulbare leegheid sonder genade. J.M. Coetzee (1985) stel die vraag wat aan die wortel van hierdie probleem lê: "What is the meaning of Africa and how can it be known? How is it possible to overcome the alienation which the European feels in Africa - that is to say: how is it possible to live in Africa?".

Die twee Stemme-romans, Hierdie lewe en Die uur van die engel, stel hierdie vraag heelwat skerper as in enige vorige roman van Schoeman. Dit gebeur omdat in hierdie romans - anders as party van die voriges - na Afrika gekyk word: nie vanuit 'n Europese afstand nie, van naby, en die kykveld is meestal die klip en stof van Afrika. As intertekstuele skakel kan foto's van die kliplandskap van Sutherland (vgl. byvoorbeeld Schoeman, 1986:23, 51) veral waarde hê om te wys hoe die optiek 'n sekere prominente eienskap van die Afrika-landskap verifieer, naamlik die uiterste onherbergsaamheid. Afrika is: "Arm land, skraal land, harde land van bossies en klip, droe spruite en fonteine van brak water ... land sonder genade ..." (Schoeman, 1993:9).

Hierdie siening van onherbergsaamheid en genadeloosheid kan impliseer dat Afrika as simbool van rykdom, soos in Afrika: 'n roman aan die orde gestel, minder belangrik word, terwyl Afrika as werklikheid ondersoek word. In Afrika: 'n roman staan Afrika vir die innerlike wondere wat ontdek sal kan word wanneer die indiwidu deur die ongekaarte streke van die gees reis: "There is all Africa and her prodigies within us" (Schoeman, 1977:63). Dit skyn 'n gegewe te wees dat die Stemme-romans hierdie inherente teenstelling tussen die moontlike rykdomme van die gees en die moeisame reis deur die onherbergsame landskap wil ontgin. J.M. Coetzee se vraag oor die lewensmoontlikhede in Afrika hang ten nouste met oorlewing saam: dit gaan vir die mens uit Europa eerstens om oorlewing, maar wanneer blote oorlewing verseker is, wat is dan in Afrika ter sake? Watter innerlike gesteldheid van die Europeërs wat hulle in Afrika in 
begewe, kom tot uitdrukking in hul verhoudinge met Afrika en ander mense in Afrika: die gee of deel van ongekende rykdomme, of wat?

\section{Dle ruimte en rulmtelike simbollek}

Hiervandaan konsentreer die ontleding op veral die twee nuimtelike dimensies, naamlik die vertikale en die horisontale, en 'n moontlike simboliese interpretasie aan die hand van 'n ontleding van manifestasies van hierdie ruimtelike dimensies.

Wanneer Lakoff en Johnson oor ruimtelike metafore skryf (1980:14 e.v.), kom hulle tot die gevolgtrekking dat 'n hele aantal assosiasies met vertikaliteit in die taal beslag gekry het, byvoorbeeld dat $O p$ (vertikaal boontoe) met geluk, bewussyn, beheer, meer, gesondheid, status en dergelike geassosieer word. Hierteenoor word $A f$ met negatiewe dinge geassosieer. Dit klop met Lotman (1977:221) se opvatting dat die bose van onder kom en die redding met 'n opwaartse beweging geassosieer word.

Die landskap in Die uur van die engel word op 'n bepaalde manier gekonsipieer, naamlik so dat daar in hoofsaak twee dimensies gesuggereer word, te wete breedte en diepte. Omdat die ruimte driedimensioneel is, ontstaan daar ' $n$ vraag na die derde dimensie, naamlik hoogte. Daar kan 'n ooreenkoms raakgesien word lussen die dimensies van die landskap en die geestelike dimensies van die mense: sekere mense beleef die landskap as 'n plat wêreld, en hierdie belewing klop met die beperkte binnewêreld van dieselfde mense. Dit is af te lees van die verhoudinge wat hulle in hul alledaagse lewens en optrede op die vlakte uitleef. Omdat 'n "vertikale dimensie" ontbreek in die lewens van party bewoners van die dorp en die vlakte, ontstaan die volgende moontlikheid: 'n strewe na die hemel ontbreek, en om hierdie beperking in romanmatige terme te illustreer, word die landskap as ' $n$ van God verlate leegheid verwoord. So word die verhouding tussen die mense en hul landskap getematiseer.

\subsection{Dle mense op dle vlakte}

Die meeste romanfigure, onder wie randfigure soos die Landmans, die Minnaars, die Engelbrechts en ander mense van die dorp en distrik wat die hooffigure omring, leef as ' $t$ ware in die vlakte ingebed. Die vlakte is in hoofsaak ' $n$ landskap wat onherbergsaam en steriel voorkom. In die Vrystaatse landskap is daar min plantegroei wat die lyne kan versag, wat groen by die wit, vaal en oker inwerk. Daar is ook geen glans in die beeld nie, soos wat groen blare in natuurlike lig sou glans. Groen staan vir groei en vrugbaarheid; vaal en bruin kom steriel voor. Die steriliteit van die lee panorama skep die probleem van oorlewing, soos eksplisiet gemaak deur die vraag wat in die elegiese slotgedeelte van Die uur van die engel deur 'n anonieme vertelstem gestel word: "Hoe moet mens lewe in hierdie kaal, harde land van klip en rots en duiselingwekkende 
ruimte en lig, en is dit trouens moontlik om selfs te oorlewe?" (Schoeman, 1995:385).

Tussen die mense op die vlakte heers daar twis en tweedrag, stryd en hebsug. Die trekboere wat die Suid-Vrystaat in die middel van die vorige eeu beset en die bewoners van destyds gewoon van die grond af druk en van die fonteine af wegwerk, demonstreer die stryd en die hebsug wat hulle aandryf. Die families wat mekaar teenstaan, byvoorbeeld die Minnaars en die Landmans, wat elk die leidende rol in die distrik wil speel, weet net van hul eie begeertes en ambisies. Dit gaan om mag, invloed en besluitneming. As die eenvoudige Danie Versies se spontane en totaal onbevange prediking hulle om politieke redes nie aanstaan nie, skroom hulle nie om middele soos die kerk en hul vermeende kerklike gesag te gebruik om hom te beveg nie. Hulle is so besig hiermee dat hulle nooit op of af kyk nie, en dus nie in staat is om saam met Danie Steenkamp en enkele ander aan die moontlikheid van engele in hul wêreld te glo nie. Die mense skyn die horisontale vlak te verkies. 'n Voorbeeld hiervan is die plek wat hulle uitsoek om hul dorp uit te lê: op die plaas Vlakfontein (waar dit meestal droog is) eerder as op die hoogte van Heuningkrans (waar daar standhoudende water is).

J.M. Coetzee (1988:9) maak die stelling dat die literatuur van die lee landskap 'n literatuur van mislukking is. Die stelling kan myns insiens ook in terme van die sogenaamde verhaalruimte gelees word. Daar is romanfigure, die reeds genoemde hooffigure soos Steenkamp en Heyns, maar ook die jong boer wat Nico na Witlaagte vergesel (Schoeman, 1995:88) wat ook die ruimte vertikaal ervaar. In teenstelling met Nico se ervaring neig die assosiasie met die berg om 'n reddende karakter te hê, in ooreenstemming met Lakoff en Johnson se tese dat beweging vertikaal opwaarts positief werk. Teenstellend hiermee: vir diegene wat net van die vlakte weet, word die leegheid 'n teken gemaak van die onvermoé van dié mense om sinvolle verhoudings met die land en mekaar tot stand te bring. In ' $n$ Ander land faal die Europeèr Versluis weens sy verwagting van vervulling byna in sy poging om met die lee landskap tot 'n vergelyk te kom. Coetzee (1988:9) konstateer: "... the task of the human imagination is to conceive not a social order capable of domesticating the landscape, but any kind of relation that consciousness can have with it". Met dic keuse van 'n landskap soos die onaansienlike vlaktes van die Suid-Vrystaat kom dit voor of Die uur van die engel met Coetzee se uitspraak in gesprek tree. Schoeman se roman konstateer: mense bemoei hulle te veel met die onderwerping van die landskap en van mekaar, mense is te min bewus van reddende moontlikhede in 'n verhouding met die landskap, en met mekaar. Hulle het nie genoeg skeppende verbeelding om iets anders as stereotiepe verhoudings tot stand te bring nie vandaar hul onvermoë om uit die horisontale dimensie te breek; hulle sit lewenslank daarin vas. 
Een van die primêre waarnemers in Die uur van die engel, die TV-persoonlikheid Nico Meiring of Nico Breedt (die dubbelnaam wil stellig die personasie-omlyning van hierdie instansie ondermyn), is ' $n$ voormalige inwoner van die dorp wat as vreemdeling terugkeer. Hy is eintlik net gedeeltelik vreemd vir die hedendaagse Vrystaatse samelewing, want hy het in sy jeug 'n paar jaar daar gewoon as seun van die skoolhoof. As argetipiese buitestaander is die volwasse Nico se vreemdheid funksioneel, want via sy redelik onbevange kyk word houdinge en verhoudinge van die waargenome wêreld gedefinieer. Die vreemdheid waarmee Nico geassosieer word, werk in 'n mate die geloofwaardigheid van sy visie in die hand. Vanwee sy agtergrond as TV-mens, immer en altyd op die uitkyk na materiaal, is die aard van sy kyk op sake egter veral artistiek gerig: dit gaan vir hom naamlik nie oor hoe die dinge werklik "is" of "was" nie, maar hoe hulle in die TV-medium voorgestel kan word.

Behalwe dat hierdie perspektief as kunsteoretiese kommentaar op die problematiek van presentasie en representasie gelees kan word, is dit binne die bestek van hierdie artikel interessant omdat dit aan die leser onthul dat ook Nico nie daarin slaag om van sy medium weg te kom nie en ewe min deur middel van sy medium tot die essensie van die ruimte deur te dring. Dit motiveer moontlik sy soektog na die verse van Danie Steenkamp; vermoedelik meen hy om daarin 'n essensiële waarheid omtrent 'n belewing van die landskap te ontdek, in 'n vir hom outentieker medium as die vals TV-beelde.

In sy wesenlike vreemdheid van die aard van die ruimte, gemanifesteer in sy onvermoes om ' $n$ engel te sien en daarin te glo, leef hy soos die meeste ander mense op die vlakte, dit is die Minnaars, Landmans en Engelbrechts van die geskiedenis. Die Nico-figuur se probleme met persoonlike verhoudinge word deur besonderhede van sy eie lewe geaktiveer (sy eensaamheid, die verlies van 'n geliefde en ontheemding - vgl. byvoorbeeld Schoeman, 1995:108 en 109). Onthullings van sy eie wêreld kenmerk dit as 'n omgewing waarin mense mekaar professioneel ondermyn en benadeel net waar hulle kan (vgl. byvoorbeeld Schoeman, 1995:44). Dit gaan om oorlewing. In hierdie opsig is daar 'n sterk ooreenstemming tussen sy wêreld en die vreemde wêreld van vroeër wat hy langs die skagte van die herinnering probeer ophaal. Laasgenoemde beweeg veel stadiger. Dit gaan oor besit en aansien in die dorp, eerder as 'n loopbaan, maar die stryd om mag, die ondermyning van teenstanders en die noodsaak van oorlewing is ook sentraal. Hierdie gegewens van Nico se lewe skakel sinvol met 'n gevoel van 'n noodlottige beweging ondertoe wat deur hom geregistreer word (vgl. veral Schoeman, 1995:45 - die gly langs die gladde helling van die gletser af, maar ook die afgrond word genoem - vgl. p. 71 en 110).

As meer ontwikkelde mens as die plattelanders, tegelyk 'n burger van 'n veel groter en woeliger wêreld as die betreklik stabiele Vrystaatse platteland én deur 
sy agtergrond tog wel gebonde aan hul perspektief, is Nico eintlik 'n inwoner van twee wêrelde. Sy bewussyn van die bestaan langs 'n afgrond kan beskou word as eksemplaries van die soort lewe waarvan sowel hy as die meeste plattelandse mense onwillige slagoffers is. Verskille tussen hom en hulle is egter eerstens dat hy besef dat hy langs 'n afgrond van vergetelheid leef; hulle (met uitsonderinge soos ds. Heyns en Danie Steenkamp) moontlik nie. 'n Tweede verskil is dat hy die enigste van daardie groep is wat laat blyk dat hy soek. Hy kon egter nog nooit die belofte verwerklik nie (Schoeman, 1995:77). 'n Interessante mate van ooreenkoms bestaan egter tussen hom en Jood de Lange. Vir Jood was die lewe op die dorp een lang stryd teen diegene wat, soos hy gedink het, hom probeer ondermyn het met 'n komplot van geringskatting. Hulle wou sy stem stilmaak, en vir hom was sy stem mettertyd al wat oorgebly het (Schoeman, 1995:204). Die ooreenkoms met Nico is in die vertikale beweging ondertoe geleë: in die laaste oomblikke van bewussyn registreer hy sy eie sterfte as 'n afsak in koue water in (Schoeman, 1995:206).

Die verskyning van die engel aan Steenkamp kan as die sentrale epiese gegewe van die roman gelees word. Rondom Steenkamp is daar skakels met sekere personasies geweef. 'n Opvallende skakel is 'n parallel tussen hom en die ietwat sukkelende ds. Heyns. Jong ds. Heyns raak met Steenkamp deurmekaar deurdat hy op die gedigte afkom, daardeur getref word en iets daarvan wil maak. Hieruit ontstaan egter ironiese klanke: die kerkgesag van ds. Heyns se eie tyd lees Steenkamp se verse as voorbeelde van die vroomheid van die voorgeslag, terwyl Heyns by sy skoonfamilie in die moeilikheid kom omdat hy nie weet van die Steenkamps se rol in die voorgeskiedenis nie.

Die parallel het 'n paar aspekte. Albei ervaar 'n visionêre oomblik: Heyns in sy jeug by die aanskoue van die magiese groen vuur op die blare van die eikeboom; Steenkamp in die veld by die aanskoue van die engel. Daar is verder die bemoeienis met taal. Albei ontdek mettertyd die ontoereikendheid van woorde. Daar is ook hul bemoeienis met mense: Danie Steenkamp rig hom aanvanklik op die hele bevolking met sy getuienis, maar word deur die invloedryke blanke boere uitgewerk totdat hy hom later tot die geringer lede van die samelewing beperk; ds. Heyns ontdek mettertyd dat hy dieselfde weg volg. Hy preek wel Sondae vir die gemeente, maar weens sy swak stem, sy taalgebruik en sy onvermoè om op die meeste gevestigde mense se geestelike golflengte in te skakel, dryf hy weg van hulle. Hy put meer bevrediging uit sy werk onder die randfigure: die armes, swakkes, sukkelendes, wat sy aandag en diens met dank ontvang. Hierdie optrede impliseer uiteraard 'n mate van verwerping van die oorwegend materialistiese establishment, 'n keuse vir die randfigure en die aanvaarding van 'n engelagtige hoedanigheid. 
'n Woordmotief wat hulle twee verbind, is konventikel, 1 wat deur Heyns opreg in sy getuienis aangebied word, maar in Steenkamp se geval as 'n doemwoord gebruik word (Schoeman, 1995:267 en 325). Een van die vele ironieë van die roman is die feit dat die hedendaagse predikant van die dorp, soos ook die jong boer van Strydfontein en tant Duifie, deel word van 'n nuwe soort evangeliebediening wat juis steun op kleingroepvergaderings en 'n intiemer soort Bybelstudie as die tradisionele kanseldiens.

Nog 'n ruimtelike skakel tussen Heyns en Steenkamp is die ervaring van die lig, 'n sekere soort lig. Die ervaring hiervan word ook net aan sekere personasies verbind. Dit is 'n lig wat Steenkamp tydens die verskyning van die engel ervaar (Schoeman, 1995:8) en Heyns, behalwe met die sien van sy vroeë visioen, tydens sy sterfte (Schoeman, 1995:303).

\subsection{Die berg}

Die oorheersing van die vlakte blyk al dadelik uit 'n vergelyking tussen die twee aspekte. Op die vlaktelandskap is daar eintlik net een berg in sig, naamlik Wonderkop, wat met sekere personasies in verband gebring word en met ander nie. Danie Steenkamp is een van die min figure in die roman wat 'n sterk bewussyn van Wonderkop toon. Hierdie kop is in die wêreld van Die uur van die engel die noemenswaardigste vertikale manifestasie op die vlakte. Wonderkop word vir Danie Steenkamp 'n baken op die vlakte (Schoeman, 1995:307). Behalwe Steenkamp is dit eintlik net die jong boer wat van Wonderkop bewus skyn te wees.

Die berg is in die Bybelse interteks 'n belangrike verskynsel. In die Bybelse ensiklopedie (Gispen e.a., 1977:99) word voorbeelde van die talle ontmoetings tussen God en mense op berge genoem, maar ook hierdie interessante inskrywing: die Arameërs het geglo dat elke godheid sy eie magsgebied gehad het, en omdat die Israeliete so baie heiligdomme op berge gebou het, het die Arameërs die godheid van die Israeliete 'n berggod genoem. Die berg is as ruimtelike verbinding tussen hemel en aarde in talle gelowe ' $n$ kragtige religieuse simbool. As axis mundi staan dit ook vir die sentrum (Lurker, 1988:85). 'n Bergpiek is die punt van kontak tussen hemel en aarde (Cirlot, 1988:219) en 'n berg is ook ' $n$ teken van "the all-embracing image of totality" (Cirlot, 1988:221).

1 Volgens die WAT (1984:293) is 'n konventikel 'n buitekerklike godsdienstige byeenkoms wat in 'n klein kring deur gebed, Bybclstudie en gesprekke die geloofslewe versterk. Daar is enersyds in pejoratiewe konnotasic, in die sin dat dit 'n sluipvergadering kan wees van 'n klein klompie mense wat iets bedryf wat hulle nie aan die daglig wil toevertrou nie. Andersyds is daar egter beslis 'n assosiasie met warmte en hartlikheid in die klein kring, wal sterk kontrasteer met byvoorbeeld afstandelike, formcle en intellektuele prediking, soos wal 'n mens soms in 'n kerk sou aantref. 
Die verbintenis met die enigste berg sluit myns insiens aan by die rol van die engel, naamlik om Steenkamp as 'n sentrale figuur aan te dui, en as 'n soort wegwyser uit te wys, iemand wat die geheim op die vlakte ontdek het. Die verbintenis tussen Steenkamp en die berg is egter nie so sterk soos die verbintenis tussen Steenkamp en engel nie. Die ruimtelike gegewens speel hier dan bloot 'n ondersteunende rol. Die berg se religieuse moontlikheid word myns insiens hier vir tematiese effek onderspeel: die engel manifesteer sigself immers op die vlakte. Dáár staan die kontras tussen genade en onherbergsaamheid skerper uit.

\subsection{Die engel}

Die uiteindelike optrede van die engel word in die "Aankoms"-deel van Die uur van die engel gesuggereer. In hierdie deel word ruimtelike attribute wat op uiterste onherbergsaamheid dui, diskursief opgestapel: die aard van die land, die afwesigheid van padwysers, die aftakeling van die huise en dies meer (Schoeman, $1995: 5,6)$. Opvallend is dat 'n geheim twee maal genoem word. Die geheim wat genoem word, kan die engel wees. Die ontdekking van die geheim op die vlakte kan 'n singewende moment wees, 'n manier om die sinlose leegheid te vul en dus te oorwin. Dit kan 'n belofte wees van iets sinvols wat gebeur het, byvoorbeeld met Danie Steenkamp, sodat die terugvind daarvan deur die hedendaagse TV-persoonlikheid, Nico, vir hom ook die vervulling van 'n belofte in sy leë lewe kan wees (Schoeman, 1995:84, 85).

Die engel op sigself, as veronderstelde manifestasie van iets of iemand buitewêrelds, dui wel op 'n vertikale dimensie, vanselfsprekend omdat die assosiasie met engele as hemelse wesens in 'n Christelike omgewing heeltemal ingeburger is. Die rol van engele as hemelse boodskappers en dienaars van mense, ook van swak mense, is welbekend en goed gedokumenteer (kyk Eliade, 1987:284).

Met die ervaring van die engel in die veld maak Danie Steenkamp hom op simboliese wyse los van die "horisontale" gemeenskap en ervaar hy 'n mistieke godsbelewing. In sy eenvoudige lewe word die geselskap van engele 'n alledaagse saak, en dus word sy lewe 'n diens aan God. In die geselskap van die engele, ondersteun deur 'n Goddelike aanwesigheid, wy hy sy lewe aan getuienis. Met 'n helder en sterk stem getuig hy en verheerlik hy die naam van God onder die mense. Die stem is, terloops, 'n opvallende motief, aangesien die hele roman aangebied word as stemme wat getuig - ook Danie Steenkamp se getuienis oor homself. Sy stem is in normale menslike omgang swak, soos ds. Heyns s'n, nie eintlik sterk genoeg vir die prediking nie, en hy het boonop 'n spraakgebrek, maar wanneer hy getuig, kom sy stem sterk en helder. Daar is opvallende parallelle met Moses op Horeb (Eksodus 3).

Deur hierdie mistieke element word moontlikhede geskep wat nog nie voorheen aangeroer is nie. Engele het die vermoe om lang stukke van die geskiedenis te 
oorleef (hulle is van die vroegste tye af deel van mense se religieuse verwysingsraamwerk, in talle verskillende godsdienste) en is selfs in die elektroniese en supersoniese eeu tuis, soos die huidige belangstelling in engele duidelik demonstreer (Du Preez, 1997:22,23). Die opvatting dat engele as boodskappers ' $n$ hemelse verbintenis in stand kan help hou, word selfs in die huidige nugter eeu aanvaarbaar gevind. Daar is immers veel meer onder die son as wat die wetenskap kan verklaar. Engele kan gesien word as in mistiek gehulde deelnemers aan die proses waarvolgens mense worstel met hul eie menslikheid, met menslike waardes en menslike waarhede. Dit is glad nie absurd nie, en dit is ' $n$ worsteling so oud soos die mens. Die intrede van die engel in die samelewing verskerp onmiddellik die fokus op die morele aspekte van die menslike bestaan, wat verklaar waarom hierdie intrede met stryd en woeling gepaard gaan. Die begenadigdes wat engele raakloop, word nie noodwendig vanwee hul kennismaking met en insig in die genadewerking van engele gewaardeer nie. Ewe min word ' $n$ belangstelling in engele verwelkom as dit met familiebelange bots.

Steenkamp en Heyns moet uitvind dat die intrede van engele en die optrede wat daaruit volg, soos Steenkamp se prediking, negatiewe emosies gaande maak: afkeuring, afguns en nyd, selfs woede. Heyns se familie het gevestigde (veral materiele maar ook sosiale) belange wat hulle eenvoudig verhinder om hulle hoegenaamd aan die Steenkamp-manifestasie van engele te steur. Op sy beste kan 'n engelverskyning daartoe lei dat 'n onskadelike sukkelaar soos Jood de Lange daarop probeer beslag l8 om vanuit die hoek van 'n gefrustreerde digter 'n bietjie glorie vir homself te probeer afsteel. Die meeste mense is doodgewoon nie in staat om die blywende en bo-menslike waardevoordeel van die mistieke engelverskyning raak te sien nie.

\section{Die vraag is: wat bly?}

Twee aanhalings uit Schoeman se oeuvre is ter sake. Eerstens die slot van Afskeid en vertrek (Schoeman, 1990:250 tot 252):

Onder die asfalt en beton stroom die water see toe, en teen die muur bot die takke van die boom, teen die glas van die geslote venster tik die bottende tak, en die uiteindelike uitkoms ofskoon verborge, is seker. Die water is sterker as die klip, en die wassende lewe in die tak sterker as die ruit waaraan dit klop; in die donker blom die blom, ongesien in helderheid (Schoeman, 1993:252).

Die liefde en woorde bly, en by implikasie ook water. Ook die lewe, gesimboliseer deur die groei en bloei van die blom, is blywend.

Hierdie slot aksentueer die vraag in die opskrif, en suggereer as antwoord dat water die blywende element is, omdat dit nuwe lewe simboliseer, omdat dit die 
geheim is wat die blom in die donker tot bloei bring. Hierdie antwoord word egter in Die uur van die engel uitgebrei.

Die vraag "Wat bly?" word die eerste keer in Die noorderlig van 1975 gestel en is minder of meer eksplisiet deurgaans in Schoeman se oeuvre soos 'n refrein aanwesig. Die uur van die engel hou 'n nuwe antwoord voor: die engel. Die durende en veral hulpverlenende eienskappe van die engel staan vas in die religieuse interteks. Dit is een van die aangrypendste manifestasies van redding en blywende genade wat nog in Schoeman se oeuvre opgeteken is.

'n Tweede aanhaling kom uit Die wêreld van die digter (Schoeman, 1986:60):

Wat bly, is die getuienis van tydgenote - want self het hulle met uitsondering van hul grafskrifte min getuienis nagelaat; wat bly, is die skrale inligting wat vanuit die hede deur 'n proses van byna argeologiese navorsing herwin kan word. Wat bly, is ten slotte 'n paar leegstaande kliphuise waar die verweerde grasdakke oor die balke inval ...

Op 'n manier is Die uur van die engel dan ook te lees as 'n antwoord op die woorde wat in bostaande aanhaling soos 'n inkantasie herhaal word: "Wat bly, wat bly". Hierin speel die ruimtelike opset 'n sleutelrol - 'n aspek wat die geldigheid van die vertrekpunt van hierdie artikel skyn te bevestig.

Blywend is die ewige landskap van stof en klip, Afrika en die ruimtelike elemente wat die redding nodig maak. Wat die bewoners in die loop van die geskiedenis bydra, is nie in staat om blywende waarde te verwerf nie. Al wat hier en daar oorskiet, is opdrifsels van die tyd. Die intrede van die engel skep egter 'n element van redding.

\section{Ten slotte}

Die slot van Afskeid en vertrek volstaan met 'n tentatiewe antwoord: taal sal altyd daar wees, en water is blywend. Die immer lewende vrug op die arbeid (of hoe 'n mens die menslike inset ook al wil interpreteer, digterlik of nie), word simbolies voorgehou as 'n blom wat in die donker bloei. Hierdie slot kan as positief gelees word: dit kan 'n vertrek op 'n artistieke reis impliseer.

Die slotwoorde van Die uur van die engel konstateer - baie soos die slot van 'n Ander land - dat die mens aan die leè landskap uitgelewer is en dat aanvaarding die enigste doenlike houding is. Hieruit ontstaan 'n sekere uitweg as 'n spesiale manier van bestaan, naamlik as 'n reis na binne: "Die reis gaan inwaarts" (Schoeman, 1995: 386). Dit skyn verder asof die slot suggereer dat daar 'n skakel kan wees tussen dié inwaartse reis en die ervaring van 'n engel. Verstrik jou in 'n stryd om oorlewing met die landskap en met die mense, en jy verdoem jouself tot 'n blote bydrae tot die 
palimpses van die geskiedenis; jy word gereduseer tot etlike kuriositeite in 'n dorpsmuseum of 'n paar patetiese oorblyfsels op vergaande papier.

Weens jou menslike aard is jy gedoem daartoe om alleen maar jou menslike beperktheid te konstateer, ongeag die medium wat jy gebruik. Die TV-dokumentêr, die bundel poësie, die kroniek van die dorp en ten slotte die Afrikaanse roman as voertuie van menslike visioene en drome is almal ewe verganklik, ewe min daartoe in staat om te sê wat nie gesê kan word nie.

Maar: maak jou los van die materie, soek die ekstra dimensie, die wonder (Wonderkop) op die vlaktes, glo die belofte, volg die engel, hoop op die visioen, en jy word deel van die lig en die lewe waar geen teken van lewe vermoed kan word nie. Daar is genade, maar dit word net aan indiwidue gegee. So gelees, word die engel op die skroeiende vlaktes van Afrika 'n stelling van 'n onverwagte en heilvooruitsig.

Dit is egter tegelyk ' $\mathrm{n}$ uiters ironiese romanslot, die stelling van "die engel van die Heer" wat "verskyn met wydgespreide vleuels" (Schoeman, 1995:386). 'n Mens onthou immers wat die lot was van Danie Steenkamp en ds. Heyns, wat albei geglo het dat 'n engel net sowel op Wonderkop as op Horeb kan verskyn. Terugwerkend dien hierdie slot dus om 'n belangrike stelling te maak oor die onvatbaarheid van hierdie boodskap in 'n durende medium wat dit waardig is.

Twee elemente konstitueer die verhouding landskap/mens in Die uur van die engel: die leè landskap en die bewoners daarvan. Skynbaar lewe alleen die bewoners. Tog, sê hierdie roman, is daar iets op die vlakte wat blywend is: die dooie klip kan tot blywende lewe gewek word, lewe wat ondanks alle vuur en hitte op die vlakte blom en tegelyk die absolute oorheersing van die totale ruimte teenspreek. Dit is die onmoontlike moontlikheid, die gloeiende donker. Die indiwidu moet dit net glo. Dit is 'n persoonlike ervaring, soos dit persoonlik en subjektief is om die spesiale lig te sien, en om die engel te sien.

Om terug te kom na J.M. Coetzee (1988:2). Die mite van 'n beloofde land wat onder die Christelike Afrikaanse trekboere posgevat het, kan sekerlik as deel van die religieuse interteks van Die uur van die engel gelees word. Hierdie artikel konstateer egter dat dié roman teen hierdie mite in skryf. Afrika is nie die beloofde land nie. Die Bybelse berge waaraan Wonderkop gekoppel word, in die sin dat God daar ' $\mathrm{n}$ ontmoeting met mense gehad het, is Horeb en Karmel, en van hulle lees 'n mens in die Ou Testament. Moses se ervaring op Horeb kan geplaas word in die tyd voor die Israeliete se uittog na die beloofde land. Hierdie parallel kan aandui dat ' $\mathrm{n}$ uittog na 'n beloofde land nog voorlê. Die vraag ontstaan dus: watter land sou 'n mens dan as die beloofde land kan beskou? Ons het immers reeds die stuk geskiedenis tussen toe en nou afgelê, en ons weet daar kan van geen ander geografiese gebied sprake wees nie. 
Met inagneming van die epiese gegewens van die roman, veral daardie verwysings na die inwaartse reis, kan 'n mens oorweeg dat die slot konstateer dat die beloofde land nie 'n plek is nie, maar ' $n$ toestand. Die aanskoue van die engel, die geloof dat dit 'n engel van die Heer is, en die aanvaarding van die begeleiding van dié wete, in kinderlike eenvoud - soos Danie Steenkamp - dit is moontlik die toestand wat bedoel word.

J.M. Coetzee vra watter verhouding die bewustheid van die vlaktelandskap kan hê. Dit is egter nie vergesog om te veronderstel dat die engel gelees kan word as 'n manifestasie van 'n argetipe uit die kollektiewe onbewuste nie. So gesien, eindig Die uur van die engel op ongeveer dieselfde punt as ' $n$ Ander land, met egter die groot verskil dat die aankoms van ' $n$ Ander land in Die uur van die engel gepresiseer word in die vorm van 'n persoonlike heilvoonuitsig vir sekere mense van die vlaktelandskap. Die engel-argetipe bewerkstellig die verbintenis met die geheim; langs hierdie weg realiseer sekere mense die belofte wat in die vlakte weggesteek word. Dit verklaar waarom mense met ' $n$ bepaalde instelling en waardestelsel, soos ds. Heyns, tannie Duifie van die dorpsmuseum en in 'n mindere mate die jong boer, heil op die vlakte vind, terwyl die terugkerende buitestaander, Nico, bedroë moet omdraai.

Afrika is egter ook ' $n$ totale ruimte, gelaai met alle moontlike waardes en beloftes. As 'n mens, soos Schoeman, die topografie as toegangsroete gebruik, kan jy sien dat die beloofde land as ' $n$ simboliese ruimte benader kan word. Die belofte is te lees as 'n sinvolle antwoord op die uitdagings wat die bar landskap rig. Volgens hierdie simboliese lesing staan die engel vir verlossing, spesifiek gekoppel aan die formulering "engel van die Heer", volgens Gispen (1977:208) 'n naam vir die Allerhoogste self in engelgestalte. Die mislukking eie aan die vlaktelewe kan op wonderbaarlike wyse oorstyg word.

\section{Bronnelys}

Cirlot, J.E. 1988. A dictionary of symbols. London \& New York : Routledge.

Coetzee, J.M. 1985. Karel Schoeman's 'n Ander land. Die Suid Afrikaan: 45-46, Maart.

Coetzee, J.M. 1988. White writing Sandton : Radix.

Du Preez, A. 1997. Stil ..I daar gaan 'n engel verby. Insig: 22-23, Feb.

Eliade, M. e.a. (reds.) 1987. The Encyclopedia of religion. Vol. I. New York: Macmillan Publishing Company.

Gispen, W.H. e.a. (reds.) 1977. Bybelse ensiklopedie. Deel 1. Kaapstad : Verenigde Protestantse Uitgewers.

Hauptfleisch, D. C. e.a. 1984. Woordeboek van die Afrikaanse Taal. Deel VII. Pretoria : Die Staatsdrukker.

Jooste, G.A. 1995. Karel Schoeman, die Afrikaanse skrywer met die Europese kyk op SuidAfrika. In: Afrikaans in een veranderende context. SAI-Reeks, no. 5. Amsterdam : Die Suid-Afrikaanse Instituut. p. 251-260.

Lakoff, G. \& Johnson, M. 1980 Metaphors we live by. Chicago \& London : The University of Chicago Press 
Lotman, J. 1977. The structure of the artistic text. Michigan : Ann Arbor.

Lurker, M. 1988. Wörterbuch der Symbolik. Stuttgart : Alfred Kröner Verlag

Schoeman, Karel. 1967. ' $n$ Lug vol helder wolke. Kaapstad : Human \& Rousseau.

Schoeman, Karel 1971. Op ' $n$ eiland. Kaapstad : Human \& Rousseau.

Schoeman, Karel. 1975. Die noorderlig. Kaapstad : Human \& Rousseau.

Schoeman, Karel. 1977. Afrika: 'n roman. Kaapstad : Human \& Rousseau.

Schoeman, Karel. 1979. Die hemeltuin. Kaapstad : Human \& Rousseau.

Schoeman, Karel. 1984. 'n Ander land. Kaapstad : Human \& Rousseau.

Schoeman, Karel. 1986. Die wêreld van die digter. Kaapstad : Human \& Rousseau.

Schoeman, Karel. 1990. Afskeid en vertrek. Kaapstad : Human \& Rousseau.

Schoeman, Karel. 1993. Hierdie lewe. Kaapstad : Human \& Rousseau.

Schoeman, Karel. 1995. Die uur van die engel. Kaapstad : Human \& Rousseau

Van Heerden, E. 1986. Toorberg. Kaapstad : Tafelberg.

Venter, L.S. 1992. Ruimte (Epiek). In: Literêre terme en teorieë. Pretoria : HAUM-Literêr. Venter, L.S. 1985. Roman sonder storie. Die Volksblad, 12 Januarie.

WAT

Kyk

Hauptfleisch, D.C. e.a. 1984.

Zoran, G. 1984. Towards a theory of space in narrative. Poetics Todory, 5(2):309-335. 
